\title{
"There's no Plastic in Our Volcano": A Story About Losing and Finding a Path to Participatory Volcanic Risk Management in Colombia
}

\author{
Jacqui Wilmshurst
}

\begin{abstract}
This chapter tells the story of a group of stakeholders who came together to collaborate on developing a more effective risk management strategy at Galeras volcano; an active and potentially extremely dangerous volcano in southern Colombia. It tells of how they came together, lost their way and then finally found the path to a truly participatory process. Woven into the story is a history of the main phases of risk communication in its widest sense, including some of the lessons learned throughout recent decades. It also extends an invitation to those involved in volcanic risk management to explore aspects of their own psychology, as an extension to the growing body of work that seeks to understand the psychology of those living with the risks. Relevant factors suggested for such an exploration include assumptions, biases, perceptions and worldviews and how these might influence, for better or for worse, the contributions being made to the field. Alongside the valuable lessons drawn from the story itself, they include the pitfalls of unexamined assumptions, the importance and value of collaborative and participatory approaches, and the essential task of ensuring that everyone is truly speaking the same language. Further applicable insights are offered from a range of other fields beyond Disaster Risk Reduction including leadership development, psychotherapy and behavioural safety.
\end{abstract}

\section{Keywords}

Risk communication - Psychology • Transactional analysis - Behavioural safety $\cdot$ Participatory approaches $\cdot$ Collaboration

J. Wilmshurst $(\bowtie)$

83 Morley Street, Sheffield S6 2PL, UK

e-mail: jakwilmshurst@gmail.com 


\section{Introduction}

On the fourth day of a week-long workshop designed to promote dialogue and co-operation between stakeholders at the base of Galeras, an active volcano just outside the city of Pasto in Nariño province, southern Colombia (see Fig. 1), an indigenous elder took the stage in an agitated state. He began to outline all the reasons that it was ridiculous to suggest that their volcano, on whose flanks they had lived and worked for several generations, could possibly contain plastic. The many stakeholders attending the University-led workshop included scientists, local and national government agencies, emergency services and at-risk communities. The indigenous elder stated that he knew there to be rocks, ash and all sorts of other materials for sure, but categorically not plastic. He spoke so fast and with such force that the official translators in the box at the rear of the auditorium gave up after the first few minutes. At this point, most of the foreign scientists left the auditorium for a tea break and the attending community members stated that they no longer wished to remain for the final days of the workshop. On discovering this, the scientists, both local and international, congregated outside to discuss how such a well-intentioned and carefully planned opportunity to create new collaboration and what was believed to be a participatory path to managing risk could have broken down so completely.

At the same time, a Colombian scientist with a sound understanding of (and concern for) the social issues surrounding risk management at Galeras, asked me whether I would be prepared to spend some time with the community members to listen to their concerns. As a psychologist, whose reason for being at the workshop in the first place was to understand better the psychological issues relating to risk management and communication, I readily agreed and a meeting was set up with key community representatives at my hotel that evening. During this meeting, I spent over two hours simply listening to the attendees of the meeting express their views, needs and frustrations; something that they had been expecting to have the opportunity to do in front of a far larger audience during the workshop itself. This airing

\section{Major Volcanoes of Colombia}

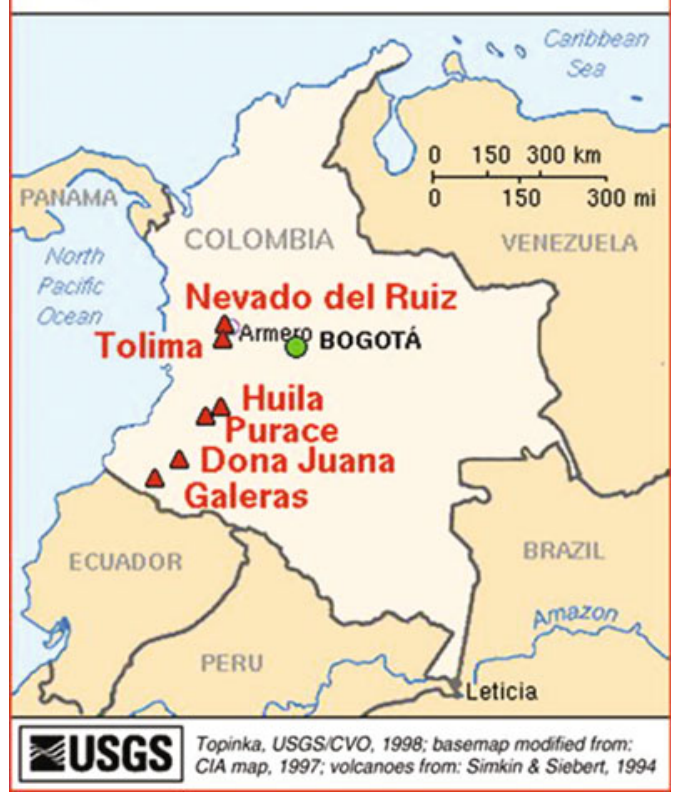

Fig. 1 Map of major volcanoes in Colombia (Source USGS)

of opinion and opportunity to be heard was to become the basis for the renewed process of dialogue communication and the rebuilding of trust that is central to this chapter.

There is an ever-expanding body of literature on the psychology of risk communication and management in the field of Disaster Risk Reduction (DRR), the primary focus of which has traditionally been on the psychology of those 'at risk'. This is of, course, an essential field of study. As a psychologist working in DRR I argue that for us to understand better a scenario such as the one presented above, there is a balance to be redressed in understanding the psychology of those whose role is to communicate and manage the risks. How those inhabiting these roles think and behave also influences the outcomes of their vital work; for better or for worse.

If you are involved in the management and communication of risks in this context, or indeed any other, then this chapter is designed both to offer you an interesting and valuable story about a journey in risk communication and management, and to invite you to take the next step towards a 
Fig. 2 Galeras volcano viewed from the eastern side of the city of Pasto (Photo Wilmshurst 2009)

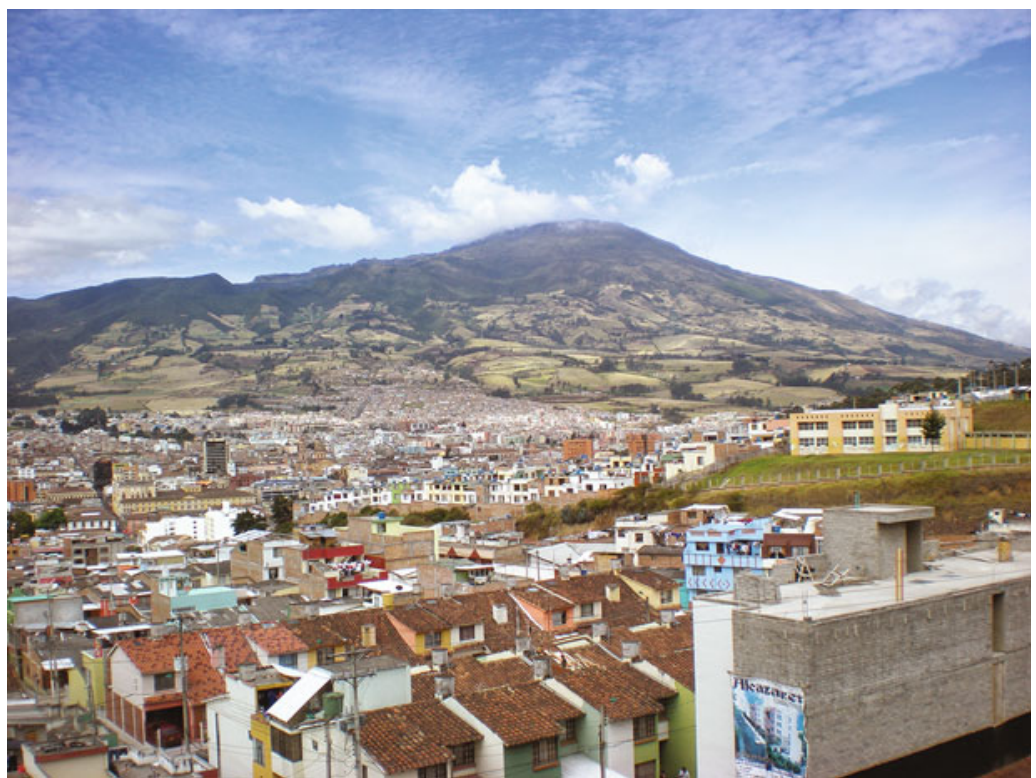

better understanding of your own thoughts, perceptions and behaviours and how they may influence the work that you do. I use this story to illustrate and introduce a range of contributions to effective practice from a variety of contexts that translate usefully to work in DRR. Learning is drawn from other applied fields such as health psychology, leadership development, psychotherapy and industrial safety, all of which also seek to understand human communication and behaviour in their respective contexts.

This story is told from my own perspective and based on my personal interpretation of events, with all the accompanying filters, biases and as yet undiscovered (and therefore unexamined) assumptions. There is absolutely no intention to criticise any of those involved, although I do aim to challenge constructively at times. The intention is to generate reflection, discussion and perhaps even changes in practice in a vitally important field of study and application.

\section{Risk Perception Around Galeras}

We will pick up the story again shortly, but first it is useful to offer some more information about the wider context in which the story unfolds.
This enables a broader understanding as to how and why initial attempts to engage with communities to create more collaborative approaches can be fraught with unexpected challenges. Especially for those who dare to try first!

The field of DRR is generally dominated in the academic realm by the applied physical sciences and is itself a relatively young field. It has taken significant time to recognise the importance of psychology and the social sciences and, as a result, the role of these disciplines is still unfolding. Early work concentrated on understanding the psychology of communities living at risk and relied heavily on work carried out in risk perception from the 1960s onwards, particularly in relation to nuclear power during those post war decades in which public consciousness of the potential dangers were at an understandable high (e.g. see Douglas 1992; Slovic 2000; Pidgeon et al. 2003).

Understanding how those living with risks make sense of those risks, and then make decisions accordingly, is certainly a good place to start. I would argue, however, that understanding the psychology of all stakeholders is not only desirable, but essential for the creation of truly effective risk management strategies that fully respect the needs and perspectives of all of those 
stakeholders. The British Psychological Society (BPS) Crisis, Disaster and Trauma section state that "recognising that the role of psychology is not only to assist in managing the psychological impact of disasters but also to play a key part in understanding how people behave (or do not behave) in the events leading up to a disaster; and engaging in planning at all stages" (ICSU 2008, p. 38). Here, 'people' can be interpreted to be all those involved in risk communication and management, not just those who may be impacted upon by the risks. There are clearly several groups of 'stakeholders' who fall into the remit of communicating and managing the risks and therefore they are no more of a homogenous entity than 'people living at risk' or 'the public'. With this acknowledgement, the intended lessons learnt from my experience is both for scientists, who primarily study the risks and seek to communicate them onwards, and for those who seek to use this scientific information to manage those risks and whose roles are often 'sandwiched' in between the scientists and those living with the risks.

Those of us who have tried it know that turning attention to an examination of oneself is generally a lot more uncomfortable than seeking to analyse others (if done honestly). The rewards are potentially enormous however; it is arguably a moral duty of anyone who seeks to involve themselves in the lives of others in ways that can have huge influence over their welfare. In other words, there is as much to be gained by scientists and risk managers taking an honest look at their (often unconscious until examined) beliefs, assumptions and biases as well as those of the people they seek to help. Otherwise they can end up, for example, openly despairing at the 'irrationality' of people who choose to live on an active volcano despite the warnings, whilst flying all over the world to warn these people of their erroneous ways at the same time as absolutely believing in human-induced climate change and yet racking up the air miles as they go! We are all contradictory by virtue of being human, and our unexamined assumptions (with consequent behaviours) can lead to the appearance of an attitude often referenced (with an intentional injection of irony) in the world of personal development consulting as; 'take my advice, I'm not using it...'.

Volcanic risk management in Colombia in the years leading up to the point in time at which the workshop took place is a complex story. The Colombian government, and indeed the population of the whole country, was dealt a huge blow when another volcano, Nevado del Ruiz (Fig. 1), erupted in 1985 killing over 23,000 people in just a few hours. Scientists had for some time been warning of an eruption and the potential for catastrophic consequences, but the country and the government had other priorities weighing heavily on them at the time, not least the civil conflict that had been raging for several decades with huge loss of life and drastic economic, social and political consequences. A retrospective examination of the events leading up to the disaster led researchers to conclude that it had been caused by “...cumulative human error-by misjudgement, indecision and bureaucratic shortsightedness." (Voight 1990, p. 1; see also Hall 1990). Only three years later, whilst this devastating disaster was still exceptionally raw and very much at the forefront of the nation's attention and psyche, Galeras volcano (Fig. 2) became active again after 10 years of dormancy. Scientists realised quickly that an eruption could occur of a great enough magnitude to cause another catastrophic disaster. It is no surprise, therefore, that the government wasted no time in giving Galeras emergency status and mobilised a great deal of resource towards averting a repeat of such a devastating event.

A feeling of panic was, of course, a fully understandable and very human response to the Nevado del Ruiz disaster. Such an emotive backdrop to the reactivation of Galeras would make it difficult for anyone (with their humanity intact) to respond with any kind dispassionate and methodical examination of the new risks posed. It is easy to see how some of the decisions made in this context would end up creating a legacy for those whose job it later became to manage the emerging risks at Galeras. One such decision made unilaterally and with lasting consequences, was to put in place a plan to relocate all communities who lived in an area deemed to 
be 'high risk' by the scientific community. The plan was designed to ensure minimal loss of life in the event of the type of eruption that scientists' research had suggested was possible, although incredibly uncertain.

There was an assumption that minimising loss of life absolutely had to be the top priority of any risk management strategy, therefore it came as a huge surprise to those who had devised the plan that there would be resistance from the communities whose lives were being so carefully protected. It turned out that there were other considerations alongside the protection of life that were featuring just as strongly, for a number of key reasons, and these were discovered later once dialogue became more open. And so it was that for a number of years an increasing 'stalemate' developed between those who felt that their role was to protect and those whose lives were being protected. It was in this context that finally, in 2009 , it was decided that an opportunity must be created to bring together scientists, risk managers and communities in order to facilitate new dialogue and co-operation in relation to the potentially devastating risks posed by Galeras. This brings us back to the workshop, with the angry and distressed elder on the stage and the future of the workshop was found to be hanging in the balance. So where did it go from here?

\section{"There Is no Plastic..."}

For three days, geologists from the UK, USA and Colombia had presented their latest scientific knowledge and understanding, relating to the unique behaviour of Galeras volcano, to the communities living on its flanks. The intention of the organisers was to give the scientists an opportunity to educate the communities as to the nature and magnitude of the risks and, as a result, to convince them of the importance of heeding the advice of the government and risk managers and, ultimately, to accept the need to be permanently relocated out of the areas deemed to be at greatest risk.

Here a wider moral question as to what we really believe the true purpose of risk communication is raised. In my experience this can be diverse and often based on unconscious assumptions on the part of those responsible for informing and shaping it. I have heard the overall purpose of risk communication and management in DRR explained as all of the following at various times; (a) to use expert information to make decisions on behalf of people living at risk should they be deemed (by those experts) not to be making optimal decisions for themselves; (b) to attempt to persuade people to act in whatever way risk communicators deem best for them; (c) to offer timely, accurate and appropriately formulated risk information so that people can choose their own actions in a fully informed way, based on integrating this information with what else that they know; or (d) to work together as equals to understand the risks from all perspectives and to design collaborative and inclusive ways in which to manage them together.

Each of these aspirations is best met using very different approaches, informed by a diverse range of work on human behaviour and relationships. For example, where better to turn to if one's goal is to persuade than the world of commercial advertising? Yet if the desire is to collaborate with those at risk such that they can make empowered decisions for themselves, consciously rather than through clever manipulation by the concerned 'experts', then the principles are entirely different. Thankfully there are ever fewer who subscribe to the intentions and accompanying beliefs contained in option (a) above. It is worth taking a moment here to consider what your approach has been so far and whether it might change once considered more carefully and consciously.

This brings us back to the business of how to examine and build a better understanding of our own psychology. When working as a consultant I use a model known as the 'conscious competence model' (Gordon International Training). The basic structure of this model is as follows; when one has not yet considered learning something new, one is necessarily then in a state of 'unconscious incompetence' (simply never having tried whatever it is and never having considered doing so-i.e. 'we don't know what we don't know'). Think of learning to drive a car. In order 
to begin learning, and before reaching the states of first 'conscious competence' (managing to drive, but still concentrating on finding the 'biting point' with each gear change) and then eventually 'unconscious competence' (arriving back home in your car via your usual route having actually meant on this occasion to go to the supermarket), it is first necessary to spend some time in a state of 'conscious incompetence' (think of early attempts at hill starts with frequent subsequent stalling!). This stage of 'conscious incompetence', however long it lasts, is a very uncomfortable one and creates a feeling known as 'cognitive dissonance'. In other words, we now know what we want to do but either cannot yet do it or are not yet doing it, for whatever reason. In health psychology and risk psychology, understanding cognitive dissonance has been instrumental in making sense of how, when we have a choice to change our behaviour or our belief (e.g. stop smoking, or convince ourselves that Auntie Ethel lived to 101 years old despite smoking heavily so it cannot be that dangerous after all). See, for example, Feather (1962), McMaster and Lee (1991), Conner and Norman (2001).

It is the same both when we decide we want to examine and better understand ourselves and when we decide we want to approach something in a different way. Like, for example, taking risk communication from an 'information deficit model' of one way communication, from 'experts' to target 'subjects', forward into a democratic, empowering and collaborative journey of discovery (The 'information deficit model' will be explained in more detail shortly.). Doing something like this requires a lot of hard work and it is very easy to slip back into what we previously knew and felt comfortable doing. This is summarised rather well by a well-loved British author of humorous science fiction Douglas Adams: "it can be very dangerous to see things from someone else's point of view without the proper training" (1995).

Another useful model for assisting a move towards better understanding the impact of our own unconscious behaviours and assumptions on those with whom we are communicating belongs to the field of Transactional Analysis (TA). Originally developed in the $1950 \mathrm{~s}$ by a psychiatrist named Eric Berne for use in psychotherapeutic practice, TA has been taken successfully (and enduringly) into fields such as leadership and management development (e.g. Wagner 1996) and industrial safety (e.g. Marsh 2014). In fact, the latter offers a good description of a facet of the model known as 'ego states', which is a way of explaining styles of communication than can influence significantly the effectiveness of our relationships (Fig. 3). The following explanation comes from the field of behavioural safety, a field which is also essentially about risk communication and management, and therefore from which we can draw much valuable learning: "the basic model is like a snowman with three bubbles on top of each other. The lower bubble represents passive, sulking behaviour. The top bubble represents aggressive, authoritarian behaviour. The middle bubble, however, is where you want to be-firm, fair, analytical and reasonable" (Marsh 2014, p. 97). Even more importantly for us, "the theory also talks of the "nurturing parent"'. This is still top bubble but without the aggression. The trouble is the side effects are that your paternal attitude may well be seen as patronising (because you are talking down to people). This mindset "will get in the way of your listening and communication" (Marsh 2014, p. 98). In understanding which bubble we are in when attempting to communicate something to another, we can gain a much better understanding of how people are likely to respond. If we are

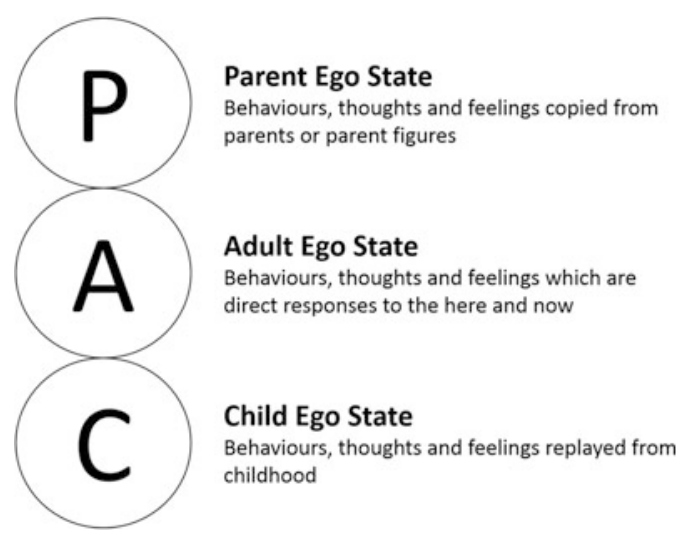

Fig. 3 Transactional Analysis Ego States Model (Source Davidson and Mountain (2017)) 


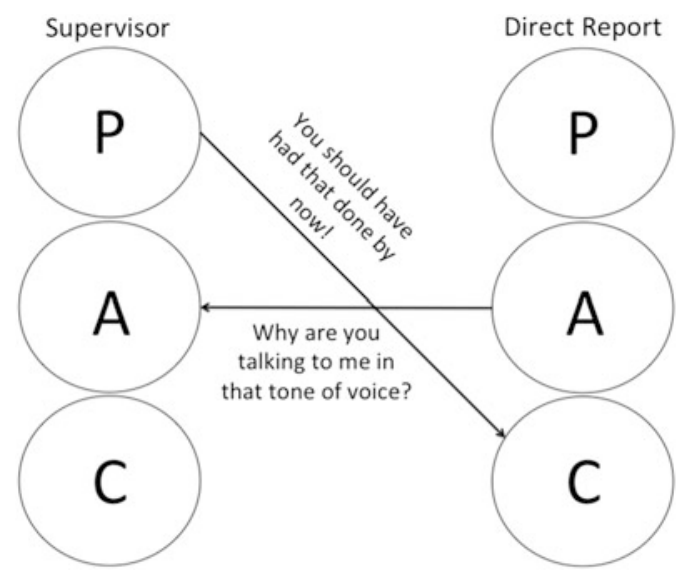

Fig. 4 Transactional Analysis Ego States: Crossed Transactions (Source Bush 2015)

able to communicate from the middle bubble, we are most likely to elicit a middle bubble response from whomever we are addressing. When we communicate (consciously and intentionally or not; more often the latter), we risk what is known as a 'crossed transaction' (Fig. 4). When this happens, we are in a situation where, for example, an inadvertently parental style may elicit a rather child-like response-for example defiance and rebellion in the face of feeling patronised and told what to do. Similarly, a crossed transaction can go the other way; a defiant or rebellious stance can elicit a parental response. Suffice to say that crossed-transactions are far messier and difficult to manage that straightforward ones! Once one understands how crossed-transactions occur, it is far easier to adjust one's own position and therefore encourage the other to move into the adult bubble also.

The plan to give the scientists an opportunity to educate the communities as to the nature and magnitude of the risks falls in line with the previously mentioned 'information deficit model'. The assumption of such a model in a risk context is that if those at risk are not taking action to avoid the identified risks, there must be a deficit either in their understanding and perception of those risks. Without examining the assumptions underlying such a deficit model, it can appear to be the most rational and obvious approach to risk communication and it is for this reason that it was the most dominant model for many years. Much has now been learned, however, about the limitations of such an approach due to the realities of human behaviour, emotion and cognition, especially in such complex risk contexts. "Information-deficit models of risk communication are simply inadequate to deal with the accumulation of data that illustrates the significance of emotional state and affective imagery" (Breakwell 2007, p. 172).

When information held by an 'expert' is deemed essential for the welfare of another it is communicated from an assumption (conscious or otherwise) of 'information deficit' and transmitted in a one-way communication designed to address this deficit, it could be said in terms of the model that one is in the 'nurturing parent' bubble. Whilst the intention is benign and caring, communicating from this bubble is more likely to trigger a 'crossed transaction' and often this is in the form of a rebellious and resistant 'child' response.

TA can help us to understand why the indigenous elder perhaps took to the stage in such an emotional state to declare that there was no plastic in their volcano. He may have been triggered into a defiant state by feeling that he was being told with great authority, by people from a faraway place, about his beloved volcano. In this state, it would have been much easier for him to hear the very technical, scientific and unfamiliar term 'pyroclastic flow' as 'plastic'.

The workshop had been set up explicitly as an opportunity for dialogue and co-operation on risk management at the Galeras volcano, with the invitation extended to all communities living in the high risk zones. Yet for the first three days these community members were given no opportunity to contribute, only to listen to a long list of scientific presentations using technical language. Great care had been taken to ensure effective translation from English to Spanish and vice versa, but the issue of translating scientific language into that which could be understood by non-scientists had been completely overlooked. This combination of oversights and miscommunications resulted in community members who felt, beyond having been invited in the first place, utterly disrespected and unheard (Fig. 5). 
Fig. 5 Elder from the indigenous community of Jenoy, featured in this story, on the stage at the University of Nariño talking about 'plastic' in their volcano (Photo Wilmshurst 2009)

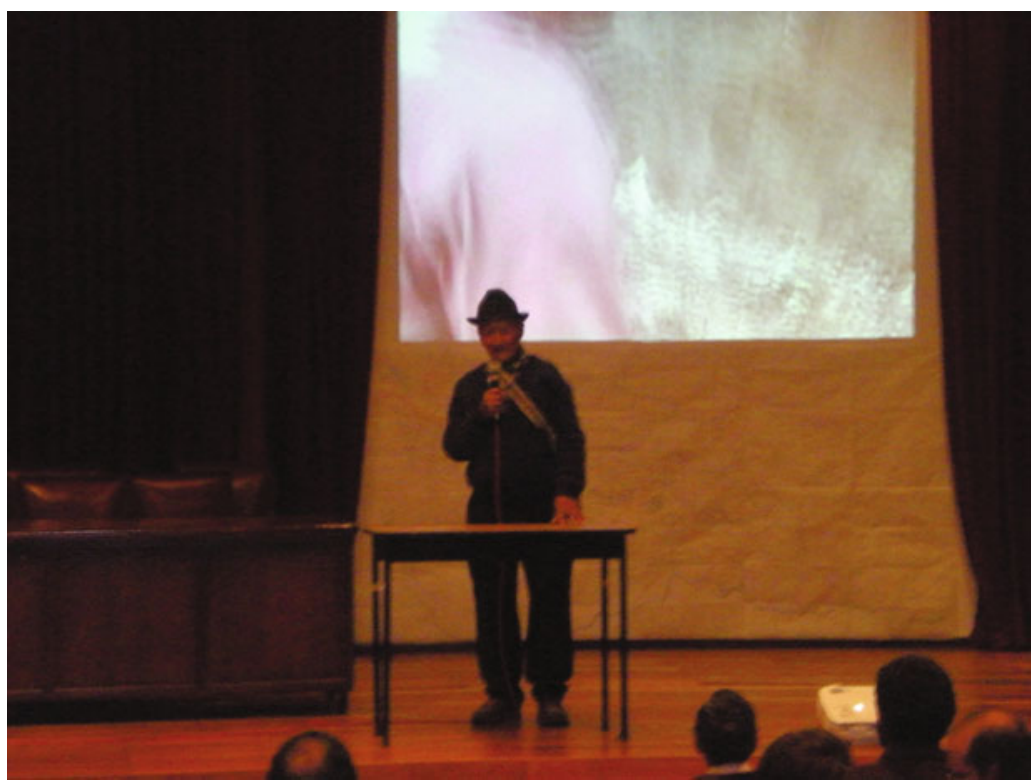

Over time, being communicated to by someone in that parental bubble, which can sometimes appear patronising and controlling, can lead to what is known as 'learned helplessness' (frequently seen in depression) where individuals simply perceive that they have no control over what is happening to them in a certain context and will stop trying to engage or change what is happening. It is worth noting that it is not especially relevant whether their perception of control continues to be accurate or not, what matters is that they stop attempting to have agency based on their perception that it is outside of their control.

The intention of all of this is not, I reiterate, to detract from the obvious importance of understanding and explaining the nature of the risks and of the way in which those risks are understood by those living with them. The challenge is how to integrate scientific information into an approach that stands the most chance of being 'effective', whatever that is decided to mean. Much has been learned about how to do this, and more of a consensus reached on the aim of risk communication in many contexts, over the past few decades of research and practice. Fischoff (1998, p. 134) offers a summary of the history of the evolution of risk communication and presents these as the first five phases:
1. All we have to do is get the numbers right.

2. All we have to do is tell them the numbers.

3. All we have to do is explain what we mean by the numbers.

4. All we have to do is show them that they've accepted similar risks in the past.

5. All we have to do is show them that it is a good deal for them.

So, if the workshop was designed and approached from the perspective of these phases, then it offers another possible part of the explanation as to why those running it encountered the same pitfalls that were encountered during this period of evolution, which ultimately led to the current understanding of what more is required to achieve better outcomes for all.

\section{Working with Different 'Ways of Knowing'}

When communicating and managing risk, trust can be undermined and therefore affect the likelihood of scientific information being well received and acted upon in a positive way. It has been found that losing trust is generally a great deal easier than gaining it, so there is much value in understanding 
how best to preserve it. This is known as 'the asymmetry principle' (Poortinga and Pidgeon 2004). Trust is a complex and multi-dimensional thing and absolutely key in effective risk communication (see Poortinga and Pidgeon 2003; Wilmshurst 2010; Crosweller and Wilmshurst 2013 for further discussion of trust in a DRR context). See also Paton's (2010) related work on people's relationships with information sources.

A more in depth understanding of biases in our decision-making, conscious or unconscious, is available through the work of Daniel Kahneman and his late research partner Amos Tversky (see Kahneman 2011). Perhaps the most common of the biases they propose and discuss is 'confirmation bias', in which we inadvertently filter out information that goes against what we already believe while seeking out and keeping only that which agrees with it.

An understanding of the biases brought into this field can offer much to the creation of a joint understanding of the perspectives and assumptions we all bring. In the case of science, an example of bias (to some degree including confirmation bias) can be in the form of what is sometimes known as 'scientism'. Broadly "scientism is a matter of putting too high a value on natural science in comparison with other branches of learning or culture" (Sorell 1994). An over-emphasis on the scientific method and its findings, leading to it being viewed as the only meaningful way of knowing about the world, can be extremely damaging when it leads to the dismissal of other forms of knowledge, including experiential. Participatory approaches in research allow for other forms of knowledge to be integrated alongside science and lead to much more collaborative and inclusive solutions, not to mention the ability to draw on a much more broader range of resources when addressing a given problem. They intentionally blur the lines between researcher and subject, creating conditions for all parties to become involved in constructing the questions, seeking methods to answer these questions and bringing different forms of knowledge to shape the answers. For more on participatory approaches, see Reason and Bradbury 2006.
One example of scientism in the context of volcanic risk, once noticed and appreciated, led to a public and very important apology. In Hawaii, myths shared and transmitted across generations about the behaviour of the volcanoes were dismissed for a long time by geologists working on the islands. Eventually, one of these geologists was forced to realise the mistake and was willing to acknowledge it openly and to apologise: "the cultural memory was right and our scientific surveys were wrong." "We were very clearly wrong and we only realised this recently. It's pretty embarrassing that geologists failed to take the Pele-Hi'iaka chants into account because we hadn't believed that the chants had any real meaning." This realisation and apology did not end there, but in fact led to a commitment to work with the locals and their myths in order to seek more insight from their own 'ways of knowing': "Swanson believes that many more scientific treasures lie in the Hawaiian chants, ready for scientists to decipher" (Swanson 2008; Palmer 2015).

I was offered anecdotal information about how the value of local knowledge at Galeras was also discovered. Stories that told of clear skies over the volcano preceding an eruption were initially dismissed by scientists, because their understanding at the time was that gas emissions (and therefore steam and cloud) would increase up to the point of eruption. It later turned out, I was told, that at Galeras there are indeed often clear skies up until the point of eruption. This is because a feature of the volcano is that as the pressure builds, the build-up of magma results in a 'plugging' effect thereby stopping gas emissions (and therefore preventing steam and therefore the resulting cloud sitting about the crater) until the pressure builds sufficiently to cause an eruption. I am not a geologist, so I cannot verify this story in terms of scientific data on the subject, but the story illustrates the importance to local people of their myths and cultural knowledge being respected alongside scientific knowledge.

As it happens, there have only been nine deaths caused by eruptions since Galeras became active again in 1989. Seven of those killed were 
scientists and two were tourists who went up to the crater with them (their story is told in Williams and Montaigne 2001). What is relevant here is the fact that the only fatalities so far have been scientists (and those accompanying them), rather than any of those living on the volcano, and this has created an unfortunate legacy in relation to local perceptions of, and trust in, scientists studying Galeras. This was only ever expressed to me alongside deep regret about the lives lost, I must add.

For more on the evolving understanding of the role of myth and other non-science based sources of knowledge see, for example, Chester (2005). There has also been relevant and interesting work on cultural theory in relation to risk perception. Douglas (1992) pointed out that the Japanese did not have a word for risk (or didn't at the time of her writing) because they did not approach danger from the viewpoint of establishing probability. This has significant and obvious implications for the subject matter of this chapter. See also Smith (1999) on the importance of uncovering and examining cultural bias when conducting research with those from other cultures who may hold world views very different than our predominantly scientific paradigm in the so-called 'West'.

\section{Rebuilding the Trust}

There has also been widespread belief among scientists that the public are unable to conceptualise uncertainty in relation to risk assessment. Many scientists have thought, as a result of this belief, that communicating uncertainty would therefore increase distrust in science and cause confusion (Frewer et al. 2003). This further points to an ongoing adherence, in some cases, to information deficit assumptions that may be taking time to shift. In contrast, research to understand effective leadership and management has repeatedly shown the value and importance of transparency and fallibility by those who seek to influence others. See also Gigerenzer (2002) for more on how different groups of people, including health professionals responsible for communicating risk, understand risk and uncertainty themselves. This links back also to the work mentioned earlier on risk as a cultural concept that is not necessarily held by all those with whom DRR professionals seek to engage (Douglas 1992).

There are a number of additional phases in Fischoff's observed evolution of risk communication, based on more recent lessons learned across the whole of the risk communication field, to which we will return later. As we will see, the workshop described above appears to have entered into the 'stakeholder engagement' phase of risk management from an (inadvertent) place of unequal status between the scientists and risk managers on the one hand, and those they were seeking to inform and protect on the other. This approach to risk communication also generally demonstrates an intention towards persuasion. In her book on the psychology of risk, Breakwell notes that "...risk communication research has focused on what happens not simply when information is being transmitted but when that information is part of a message that is designed to persuade. The persuasion is aimed at making the recipients see the hazard in a different way and as a consequence change their attitude or behaviour towards it" (2007, p. 131). There is a huge and growing body of work on how to persuade people to engage in 'behaviour change' in various contexts (see Marsh 2014 to learn about 'nudge' theory and the very effective behavioural change intervention using a plastic fly in a urinal to improve hygiene in public toilets). For the purposes of this chapter and because of the nature of the DRR context, however, we are going to move on to those approaches that seek to be fully inclusive and participatory.

As a psychologist, I had been invited along to the workshop to assess whether it would be a viable case study for a research project to explore psychological risk factors in volcanic risk management. Clearly I had my answer at this point! The intervention by one of the local scientists that I mentioned earlier, who was really concerned that the hard work and good intentions were potentially about to be lost, was a major turning point. Once I had offered to spend some 
time learning more about the perspectives, concerns and experiences that the community members had come along hoping to share, the energy changed and community participants agreed to re-engage in the workshop. Following this necessary and important clearing of emotional energy the way was finally cleared to get a range of stakeholders in a room to begin new dialogue.

Another meeting was organised for the next day and more emotional expression was needed and allowed before things could move on. This was especially important as this next meeting happened to fall on the anniversary of the Nevado del Ruiz disaster and there were people in the room who had lived through the devastation and loss first hand. Eventually, the subject matter turned to the future and the desire to find a more effective may forward was universally shared. From this new place, it was possible for the group to produce three lists, together, outlining the issues that all stakeholders present agreed on. These lists were; 'Points of Agreement', 'Points of Conflict' (they were surprised to find that they actually agreed on what the points of disagreement were and this provided a significant breakthrough in trust and understanding between the group members at this point) and 'Conclusions of the Workshop' (which included the need to review current decrees, laws, policies etc. and most notably the proposed plans for enforced relocation). The group included representation from national and local risk management bodies, communities living in the high risk zones and local scientists. International scientists were not represented as they were in a parallel session to discuss the communication of scientific uncertainty.

From the production of these lists, and agreement that all now felt that they had been given an opportunity to be heard more fully, came an agreement to embark on a new process of dialogue and collaboration between the stakeholders. The process would be facilitated and explore what could be done to take them forward, using their lists of agreement and of agreed areas of continued disagreement and conflict as a guide. Thus the step was taken from an approach based on 'information deficit' and the need for persuasion and therefore from the one-way presentation of scientific data of Fischoff's step five, into the final three phases of his journey of risk communication:

6. All we have to do is treat them nice.

7. All we have to do is make them partners.

8. All of the above.

Thankfully most risk management strategies have now started to move away from an approach that suggests that it's all about risk perception, a deficit of knowledge (and the accompanying need to educate people about the risks until they understand enough to do as the scientists are telling them) towards approaches that are collaborative and participatory (e.g. John Twigg 2009). There is still a legacy of the old approaches apparent in some areas, however, and therefore more work to be done.

Participatory methods have been gaining ground rapidly in DRR in recent years, not least due to the evidence of how effective they are in creating sustainable strategies that draw on the wide range of knowledge and resource made available by such collaborative methods. One cautionary note worth making here is that they do, however, need to be truly participatory rather than approaches that appear to engage all stakeholders but that ultimately consist of officials seeking endorsement of decisions already made (confirmation bias at work) and mistaking this for collaboration and participation. Breakwell (2007, p. 172) notes that:

\footnotetext{
Risk communication is a mammoth topic...in moving from an examination of the classic literature on persuasion through to the discussion of consultative and participation methods, it echoes the journey made by risk communication and philosophy over the last half-century. There has been a move from seeing the public as targets for influence to recognising them as partners of in the process of risk management. Of course, not all institutions have made this move and not all risks are particularly amenable to it.
}

Her last point is vital, and there will no doubt continue to be spirited debate about which hazards and risks are, and are not, amenable to 
participatory approaches in the field of DRR and beyond. What should be avoided, however, is the use of non-participatory approaches simply because they are perceived to be less time and resource intensive and more comfortable and familiar, rather than because they best suit the context and needs of the people affected by them.

So, as the workshop concluded in the beautiful surroundings of La Cocha Lake in the hills to the east of Pasto, the participants of the group that had come together as a result of the breakdown part way through had made a commitment to meet again and to build an ongoing partnership. Here began a three month facilitated process of dialogue and collaboration back at the university in Pasto, to build a more participatory approach to risk management at Galeras volcano. Members of the group represented the local science community, the university, local and national disaster management groups and organisations and three of the communities living in the high risk zone on the flanks of the volcano. The process was named by the group, very aptly, 'Speaking the Same Language'. Whilst I guided and facilitated the process, all content was created and decisions made by the members of the group. It was agreed that the group would follow, albeit loosely to allow for flexibility, an 'action research' approach
(Reason and Bradbury 2006). As part of this, the members drew up and reached consensus on a group objective and a set of group working 'rules' for the facilitation period (Figs. 6 and 7).

At the start of the process, solutions suggested by the officials responsible for managing volcanic risk centred on two main areas: (a) permanent relocation in the medium to long term for those living in the designated high risk areas of 'red zone' and (b) in the more immediate term and for those living outside the 'red zone' (high risk zone), having a well-practised evacuation plan in the event of a significant eruption being forecast. Many of the community members wanted to start from a place of open discussion about the suitability of the proposed (and in some areas partially implemented) plans. This included reaching agreement between all stakeholders on the nature and extent of the risks posed. Also, arriving at solutions that would satisfy 'officials' that the people whose interests they sought to serve were making sound and informed decisions about their safety and welfare. In a wider DRR context, the moral question remains as to who should have the final say in what constitutes sound and informed decisions and optimal behaviours, and with whom the responsibility to ensure behaviours are carried out ultimately lies.
Fig. 6 Members of the group working together on a more inclusive risk management strategy (Photo Wilmshurst 2009)

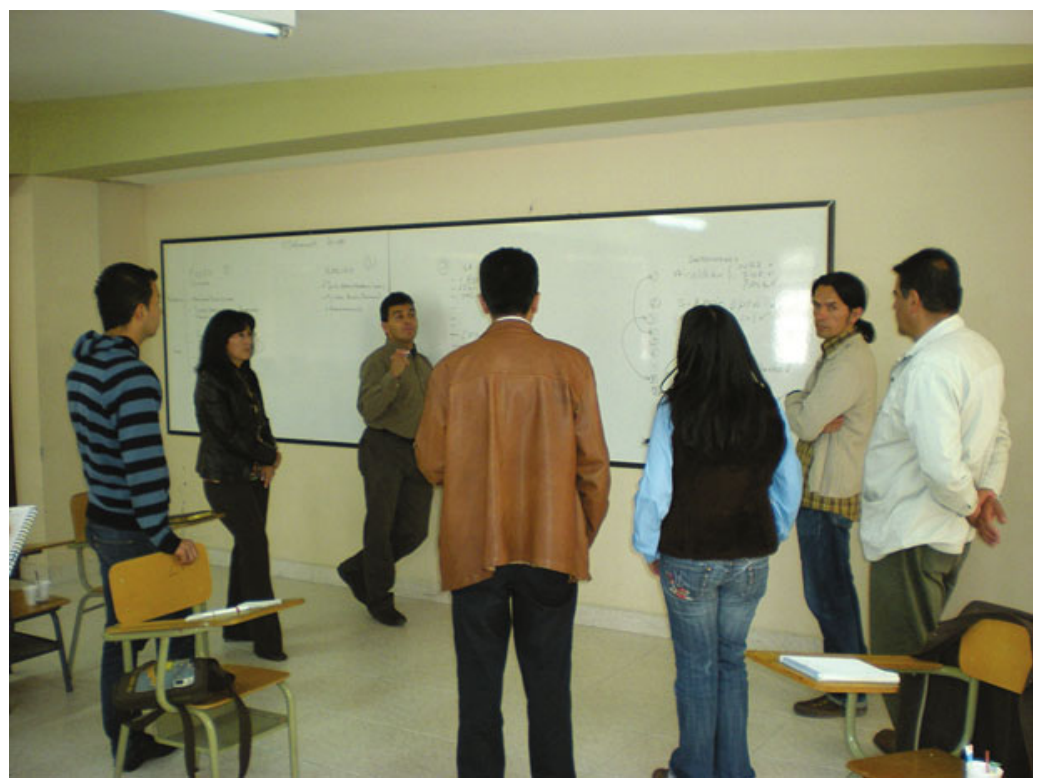


This is a question that permeates much of the risk literature in relation to health and safety as a whole, but certainly there are many more ambiguities in a situation such as this. There is, however, plenty of evidence to show that enforcing compliance in a 'top down' manner without genuine engagement with all parties is generally far less successful than approaches that allow all to have a genuine part to play in how a culture of good risk management is developed (Marsh 2014). For this reason, despite some obvious and important differences, there is much of value to DRR to be found in the world of industrial safety management.

The process ran from September until December 2009. At end of this first facilitated period, the group felt no further need for me as the facilitator (as was hoped and intended at the start, as the process was designed to work towards empowering the group to continue in a self-regulating manner). They had by this point identified and brought together a much wider group of important stakeholders, including representatives from further disaster management bodies and various government departments including, importantly given the nature of the risks, the department of health.
Things did not always go smoothly, of course, and we lost important representatives from one of the communities about one month into the process. This was due to an impasse relating to the presence of officials deemed by them to be essential for the process. These community members, from the indigenous community of Jenoy, were also at this time working hard to gain recognition from the government of their indigenous heritage and membership of the Quillasinga people. I am pleased to report that they had made significant progress on this when I visited them the following year. Following both their departure and the end of the facilitated period, it was also decided that 'communities' could no longer be a homogenous part of the group membership, as each community had different environments (literally in terms of living at different altitudes on the flanks of the volcano and therefore producing different crops and keeping different livestock). They also had different cultural, needs and priorities. It was therefore decided that representatives from each community would engage with risk managers independently until such time as they felt able to come back together as one group. As well as differences between them, there also emerged
Fig. 7 Galeras volcano overseeing our work: the view from our meeting room within the University of Nariño (Photo Wilmshurst 2009)

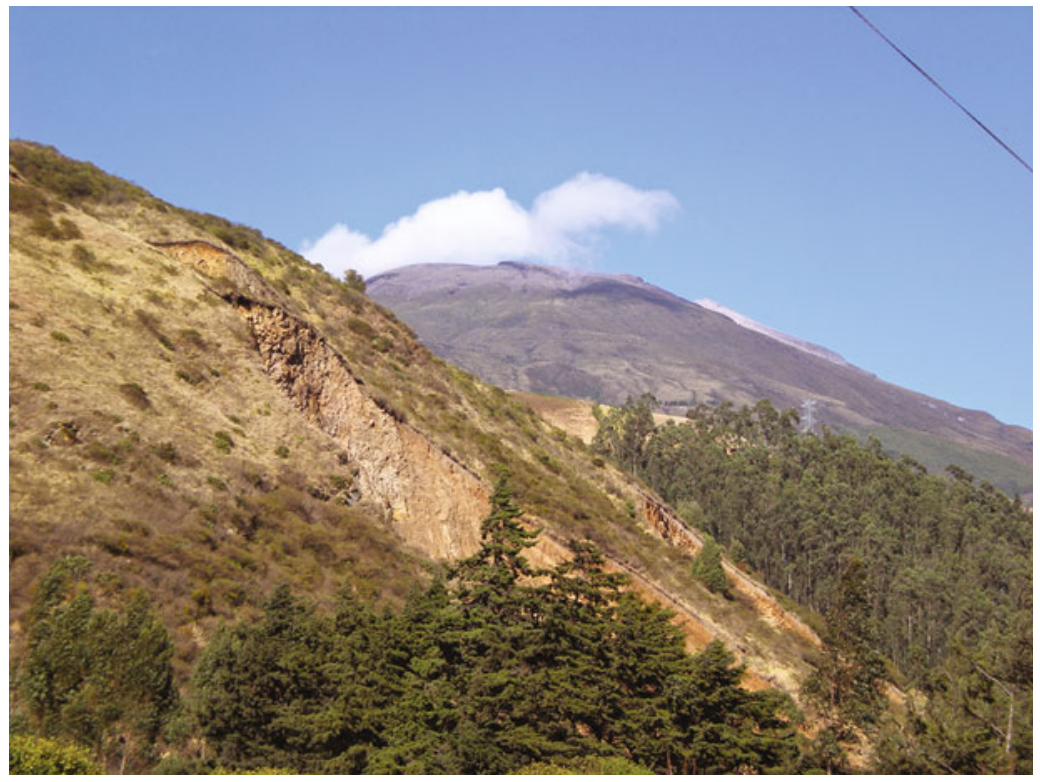


interesting and important differences in perspective amongst the young and the elders within the respective communities. A further very important consideration that emerged from the process was the fact that whilst the scientists and risk managers were mostly viewing the volcano as a potential hazard, the communities living on its flanks were seeing it as both a potential hazard and a huge source of opportunity. The opportunities include very fertile soil for growing crops, hot springs for bathing and their many myths and stories that being them close to their 'Taita Galeras' as a spiritual connection to their culture and their roots. For more on the more recent acknowledgement of the importance of volcanoes as opportunities as well as hazards, and how these perceived benefits can offset the risks, see Kelman and Mather 2008.

It emerged too that the way in which the community members were considering the risks was from a far broader perspective, and were taking into account other threats and relative considerations, than those of the risk managers. This is not surprising given that the focus of risk managers and communicators is usually from the point of view of a particular hazard, risk or set of priorities. Again, an examination of the assumptions inherent in that is hugely valuable and can avert a number of problems. In this case, it emerged from the conversations that despite the obvious fear of a large volcanic eruption following the Nevado del Ruiz disaster, there was a recognition that the risks of an earthquake are also very significant given that Pasto sits very close to a major fault line and has been affected by a number of large earthquakes in the past. This has important potential implications when considering relocating these communities from the flanks of the volcano into a city living at risk of powerful earthquakes. Community members resisting relocation to the city also pointed out that, to them, the loss of their culture and practices and their community cohesion was potentially a bigger threat to them than losing their lives to an eruption. This again surfaced the assumption that preventing loss of life should necessarily be the sole focus of risk management strategies. The request was instead that quality of life be held in equal regard by those managing the risks.
I left the process at the end of the agreed phase of facilitated work, at which point there was a fantastic level of motivation and commitment to continue to work in a collaborative and participatory way, in spite of the many hurdles and frustrations inherent in such an approach. The last time I had contact with members of the group they were continuing to progress, learn and further develop strategies together, although not without significant challenges. There was however thankfully still no desire to return to earlier approaches after all that had been gained and learned through such an inclusive approach.

\section{Conclusions: Speaking the Same Language}

This experience has taken us on a journey through Fischoff's stages of the evolution of risk communication and collected additional learning from other fields along the way. The intention was two-fold: firstly, to tell you a story about how a group of people came together from a place of mistrust and miscommunication to build a participatory approach to managing risks at Galeras volcano. Secondly, to use this story to bring to life a range of lessons and contributions from DRR and beyond as an invitation to you to think about your own role in DRR and the range of psychological factors you bring to what you do, including a whole collection of assumptions, biases, perceptions and beliefs.

The lessons learned through getting lost and finding the way again are many, but they can be centred around a few key areas. The journey of risk communication has been one of building layers, rather than of moving through and beyond distinct stages. This is important because it means that we need to hold on to the learning and contribution of each stage and keep learning about who is best placed to achieve each and how. This allows for all stakeholders to play their part in risk management processes that are truly inclusive and integrated, and which allow us to benefit from the immensely rich learning available from, for example, cultural memory, lived experience and lay-persons' observations alongside scientific 
inquiry. In bringing together stakeholders to work together, mistakes are inevitably made and many more lessons are learned, usually more quickly if at times a little more painfully! When the conditions are created for open, honest and respectful communication, assumptions are surfaced and can be worked with and through consciously. Through this, inadvertent biases can be removed, intentional ones can be challenged, and relationships will be both more effective and usually more enjoyable.

It is important, alongside continuing to develop the interdisciplinary nature of DRR by bringing in relevant academic disciplines, to continue to seek applicable learning from other fields involved in understanding human behaviour, relationships and communication. This not only opens the door to many more sources of rich learning, but helps us to minimise how many painful lessons we must learn for ourselves when others have already been there first.

When we make this into a conscious journey and maintain an open mind and a collaborative spirit, we stand the best chance of bringing about solutions in which we truly all are speaking the same language.

Acknowledgements Sincere thanks to all of those with whom I have worked at Galeras volcano in Colombia. May your perseverance, humility and ever-evolving insight continue to inform and inspire.

\section{References}

Adams D (1995) The hitch hiker's guide to the galaxy: a trilogy in five parts. William Heinemann

Breakwell GM (2007) The psychology of risk. Cambridge University Press

Bush D (2015) 'When Supervision Becomes Parenting' https://www.linkedin.com/pulse/when-supervisionbecomes-parenting-douglas-bush-m-a- (Accessed 7 May)

Chester DK (2005) Theology and disaster studies: the need for dialogue. J Volcanol Geoth Res 172 (3-4):319-328

Conner M, Norman P (eds) (2001) Predicting health behaviour. Open University Press

Crosweller H, Wilmshurst J (2013) Natural hazards and risk: the human perspective. In: Sparks S, Hill L (eds) Risk and uncertainty assessment for natural hazards, Cambridge University Press
Davidson C, Mountain A (2017) "Transactional analysis". http://www.businessballs.com/transactionalanalysis. htm (Accessed 15 Mar 2017)

Douglas M (1992) Risk and blame: essays in cultural theory. Routledge

Feather NT (1962) Cigarette smoking and lung cancer: a study of cognitive dissonance. Aust J Psychol 14(1):55-64

Fischoff B (1998) Risk Communication. In: Lofstedt R, Frewer L (eds) Risk and modern society. Earthscan, London

Frewer LJ, Scholderer J, Bredahl L (2003) Communicating about the risks and benefits of genetically modified foods: the mediating role of trust. Risk Anal 23:1117-1133

Gigerenzer G (2002) Reckoning with risk: learning to live with uncertainty. Penguin Books

Gordon Training International. 'The Conscious Competence Model': www.mindtools.com/pages/article/ newISS_96.htm

Hall M (1990) Chronology of the principle scientific and governmental actions leading up to the November 13, 1985 eruption of Nevado del Ruiz, Colombia. J Volcanol Geoth Res 42(1-2):101-115

ICSU (International Council for Science) (2008) A science plan for integrated research on disaster risk: addressing the challenge of natural and human-induced environmental hazards. ICSU, Paris www.icsu.org/publications/reports-and-reviews/ IRDR-science-plan

Kahneman D (2011) Thinking fast and slow. Farrar, Straus and Giroux

Kelmanm I, Mather TA (2008) Living with volcanoes: the sustainable livelihoods approach for volcano-related opportunities. J Volcanol Geoth Res 172(3-4):189-198

Marsh T (2014) Talking safety: a user's guide to world class safety conversation. Gower

McMaster C, Lee C (1991) Cognitive dissonance in tobacco smokers. Addict Behav 16(5):349-353

Palmer J (2015) Why ancient myths about volcanoes are often true. http://www.bbc.co.uk/earth/story/20150318why-volcano-myths-are-true (Accessed 6 May 2017)

Pidgeon N, Kasperson RE, Slovic P (eds) (2003) The social amplification of risk. Cambridge University Press

Poortinga W, Pidgeon NF (2003) Exploring the dimensionality of trust in risk regulation. Risk Anal 23(5):961-972

Poortinga W, Pidgeon N (2004) Trust, the asymmetry principle, and the role of prior beliefs. Risk Anal 24 (6): $1475-1486$

Reason P, Bradbury H (eds) (2006) The handbook of action research. Sage

Slovic P (2000) The perception of risk. Earthscan, London

Smith LT (1999) Decolonising methodologies. Zed Books

Sorell T (1994) Scientism: philosophy and the infatuation with science. Routledge

Swanson D (2008) Hawaiian oral tradition describes 400 years of volcanic activity at Kîlauea. J Volcanol Geoth Res 176:427-431 
The Information Deficit Model. https://en.wikipedia.org/ wiki/Information_deficit_model. (Accessed 30 Apr 2017)

Twigg J (2009) Characteristics of a disaster-resilient community: a guidance note. University College London, www.abuhrc.org/research/dsm/Pages/project_ view.aspx?project=13 (Accessed 15 Mar 2017)

Voight B (1990) The 1985 Nevado del Ruiz volcano catastrophe: anatomy and retrospection. J Volcanol Geoth Res 42(1-2):151-188

Open Access This chapter is licensed under the terms of the Creative Commons Attribution 4.0 International License (http://creativecommons.org/licenses/by/4.0/), which permits use, sharing, adaptation, distribution and reproduction in any medium or format, as long as you give appropriate credit to the original author(s) and the source, provide a link to the Creative Commons license and indicate if changes were made.
Wagner A (1996) The transactional manager. The Industrial Society

Williams S, Montaigne F (2001) Surviving galeras. Houghton Mifflin

Wilmshurst J (2010) Living with extreme weather events: an exploratory study of psychological factors in at-risk communities in the UK and Belize. Unpublished $\mathrm{Ph}$. D. thesis
The images or other third party material in this chapter are included in the chapter's Creative Commons license, unless indicated otherwise in a credit line to the material. If material is not included in the chapter's Creative Commons license and your intended use is not permitted by statutory regulation or exceeds the permitted use, you will need to obtain permission directly from the copyright holder. 